\title{
Editorials
}

\section{Closing the gap between physical and mental health training}

\section{INTEGRATION AND PARITY OF ESTEEM}

Mental illness and physical ill health are inextricably linked. Separating the two has led to significant health inequalities and barriers to health care for some of our most vulnerable patients. In March this year, the King's Fund built on findings from the Independent Mental Health Taskforce to the NHS in England's Five Year Forward View for Mental Health ${ }^{1}$ by publishing Bringing Together Physical and Mental Health: A New Frontier for Integrated Care. ${ }^{2}$ Both documents emphasise the need to integrate physical, mental, and social care. The latter cites the factors that have led us to this point:

institutional and cultural barriers, separate payment systems for physical and mental health care, and the trend for increasing sub-specialisation in professional education.'2

New approaches should ensure that mental and physical health needs are considered together and that people with a mental disorder have equal access to services for their physical health as others.

This is not an original concept. 'Parity of esteem', the principle of affording equal value to mental and physical health, was enshrined in statute within the Health and Social Care Act 2012. Despite this, the scale of the physical health gap between those with chronic mental illness and those without remains vast. Those with severe mental illness are less likely to attend routine screening ${ }^{3}$ or access medical assistance. People with bipolar affective disorder and schizophrenia are, on average, likely to die 15-20 years earlier than those without. 'Approximately two-thirds of these deaths are from potentially modifiable risks and diseases such as smoking, obesity, diabetes, ischaemic heart disease, and malignancy.

The relationship between physical and mental health is bidirectional. Depression is approximately two to three times more common in people with a chronic physical health problem than in people who have good physical health. ${ }^{4}$ Symptomatology, stigma, socioeconomic inequalities, and diagnostic overshadowing all contribute to the barrier preventing access, as can interprofessional fragmentation and confusion over who is responsible for providing care.

\section{The management of these frequent attenders in primary care is costly and rarely satisfactory...}

\section{CHANGING MODELS OF MENTAL HEALTH TRAINING FOR GPS}

You should consider the mental health of a patient in every primary care consultation: $90 \%$ of people with mental health problems across the lifespan are managed in primary care. $^{5}$

The mind-body connection is constant. Independently, both psychiatrists and GPs are urged to consider this routinely, but the more complex cases could provide opportunities for joint learning. Medically unexplained symptoms account for an estimated one in five new consultations in primary care and $52 \%$ of those in secondary care. ${ }^{6}$ The management of these frequent attenders in primary care is costly and rarely satisfactory for anyone. When sinister reversible causes have been excluded, the practitioner may inadvertently assign lesser significance to the illness. The patient can then be left feeling that mental illness is not as serious and that they are in some way to blame for their symptoms. Until any underlying psychological component is addressed appropriately, the patient will continue to present with physical health issues. There exemplifies the need and opportunity for the specialties of general practice and psychiatry to move away from silo working and integrate skills to improve the health of those with mental illness. This would provide a coherent experience for patients, a fulfilling one for doctors, and potentially reduce excess treatment costs.

GPs are traditionally the leaders in holism, but, in the absence of mandatory formal mental health placements, have we been adequately preparing our trainees? Experience of how mental health services operate, and the interface with social care, is important for understanding the realities of secondary mental health care and to learn how to accurately risk assess. Reciprocally, GP trainees are hugely valued by mental health teams for their knowledge of physical health care and its management.

Recent moves have been made to ensure more trainees experience psychiatry as part of their postgraduate posts. The Broadening the Foundation Programme report ${ }^{7}$ has recommended that $100 \%$ of foundation year doctors should have a community post within their training from August 2017, 45\% of these should be in psychiatry. Deaneries are adapting GP specialty programmes as well. For example, within the Health Education Kent, Surrey and Sussex deanery, most trainees already either have a full-time 4-month psychiatry placement or an integrated training post placement in psychiatry. The remainder $(<5 \%)$ have a personalised plan to address mental health in their GP placements (C Warwick, personal communication, 9 June 2016).

These developments are distinct from the long-held desire for enhanced and extended general practice training, from 3 to 4 years, to lamong other aims) accommodate placements in the priority area of mental health. ${ }^{8}$

Yet what do these changes mean practically for our trainees, who will be working with patients to navigate the rigid lines of the mental health system?

\section{MUTUAL RESPECT AND COLLABORATION} THROUGH MEDICAL EDUCATION

The authors of this editorial are a new consultant psychiatrist and a recently
"There exemplifies the need and opportunity for the specialties of general practice and psychiatry to move away from silo working and integrate skills 


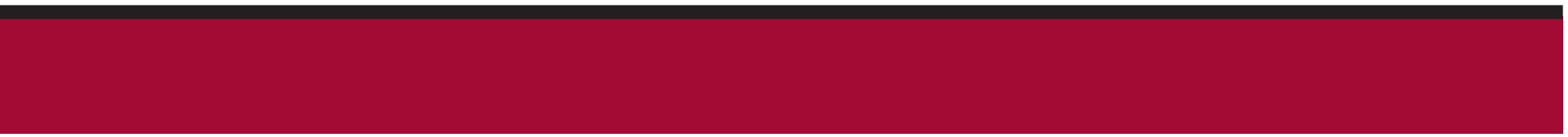

“... 22 (InnovAiT) podcasts have been downloaded nearly 14000 times ... half of which have contained psychiatry segments...

qualified GP. We believe that collaboration can enhance learning, shift perceptions, and strengthen relationships. In 2013, InnovAiT, the Royal College of General Practitioner's (RCGP's) education journal for GPs and GPs in training, began to produce podcasts based around the GP curriculum. Importantly, it collaborated with other specialties. To date, 22 podcasts have been downloaded nearly 14000 times for free via iTunes and the InnovAiT webpage, half of which have contained psychiatry segments ranging from condition-focused elements on depression and schizophrenia to physical health needs and social issues experienced by patients with mental illness. Furthermore, it has explored mental wellbeing in the workplace for GPs and produced a whole edition on professional resilience. The educational potential of multimedia to supplement training across traditional borders of deaneries and countries at low cost and high convenience for all parties is clear and allows a timely response to the demands and schedules of modern medicine. In the case of InnovAiT podcasts, they not only offer opportunities to educate GP trainees in psychiatry but, importantly, psychiatry (and other) trainees in general practice.

Shared learning opportunities can also clearly be developed within more traditional models of learning. Combined psychiatric and primary care teaching sessions could be formed to explore the biopsychosocial model underpinning challenging chronic mental and physical illnesses. Both community psychiatric and general practice posts can be adapted to enable a broader understanding of these aspects of illness; be they through home visits (currently reserved for the housebound and acutely unwell), experience of psychological therapies, and social prescribing measures. The aim would be to invigorate and enhance practitioners' abilities to provide and coordinate care for patients and, importantly, be able to offer hope. This will create a better experience for the patient and doctor.

\section{A SHIFT IN EXPECTATIONS}

While acknowledging the challenges of parity of esteem for patients we recognise that both our specialties also experience inequality. A recent survey investigated medical students' perception of status between specialties and whether they had witnessed disparaging comments against specialties. ${ }^{9}$ Psychiatry and general practice attracted the most negative comments from all grades. This had direct effects on career choice for some students, while others kept their selection to themselves for fear of discrimination. Understanding more about each other's specialty is key, as is not being guilty of making these comments ourselves. To highlight and discourage this derision the '\#banthebash' campaign was recently launched by the Royal College of Psychiatrists and, swiftly, supported by the RCGP; see also the editorial by Baker and colleagues in this issue of the BJGP. ${ }^{10}$

Traditionally physical health care has been considered a minor focus of the psychiatric remit. As we focus on better equipping our future GPs to assist patients with mental health needs, we propose a parallel call for enhancing physical health care within psychiatric training. A psychiatry trainee rotating through general practice would be mutually beneficial and akin to the current advantages we already realise for general practice trainees. If we are to ever truly reach parity of esteem we must consider seismic changes in the delivery of our services. Why not start with training?

\section{Simon Glew,}

Honorary Research Fellow, Brighton and Sussex Medical School, Division of Primary Care and Public Health, Brighton.

\section{Beth Chapman,}

Locum consultant psychiatrist in community child and adolescent mental health, Cornwall Partnership NHS Foundation Trust

\section{Provenance}

Commissioned; externally peer reviewed.

\section{Competing interests}

Simon Glew is the founder and editor of InnovAiT podcasts. Beth Chapman contributed regular psychiatry segments to InnovAiT podcasts between 2013-2015.

DOI: 10.3399/bjgp16X687157

\section{ADDRESS FOR CORRESPONDENCE}

\section{Simon Glew}

Brighton and Sussex Medical School, Division of Primary Care and Public Health, Mayfield House, Falmer, Brighton, BN1 9PH, UK.

\section{E-mail: s.glewabsms.ac.uk} aSi_Glew

\section{REFERENCES}

1. NHS England. Mental Health Taskforce. The five year forward view for mental health. A report from the independent Mental Health Taskforce to the NHS in England. $2016 \mathrm{https}: / / \mathrm{wmw}$. england.nhs.uk/wp-content/uploads/2016/02/ Mental-Health-Taskforce-FYFV-final.pdf (accessed 5 Sep 2016).

2. Naylor, C, Das, P, Ross, S, et al. Bringing together physical and mental health. A new frontier for integrated care. 2016. http:// uww.kingsfund.org.uk/sites/files/kf/field/ field_publication_file/Bringing-together-KingsFund-March-2016_1.pdf (accessed 5 Sep 2016).

3. Royal College of Psychiatrists. Whole-person care: from rhetoric to reality. Achieving parity between mental and physical health. Occasional Paper OP88. London: Royal College of Psychiatrists, 2013.

4. National Institute for Health and Care Excellence. Depression in adults with a chronic physical health problem: recognition and management. CG91. 2009. https://www.nice.org uk/Guidance/cg91 (accessed 5 Sep 2016).

5. Royal College of General Practitioners. The RCGP Curriculum. Clinical modules 3.10 Care of people with mental health problems: summary. 2016. http://www.rcgp.org.uk/ clinical-and-research/toolkits/ /media/ B9B066784CED42518D2E5F80E141D504.ashx (accessed 5 Sep 2016).

6. Improving Access to Psychological Therapies NHS. Medically unexplained symptoms/ functional symptoms. Positive practice guide. 2014. http://uww.iapt.nhs.uk/silo/files/medicallyunexplained-symptoms-postive-practiceguide-2014.pdf (accessed 5 Sep 2016).

7. Health Education England. Broadening the foundation programme. Recommendations and implementation quidance. 2014. https:// hee.nhs.uk/sites/default/files/documents/ Broadening\%20the \%20foundation\%20report.pdf laccessed 5 Sep 2016).

8. Royal College of General Practitioners. Enhanced and extended GP training progress update. 2013. http://www.rcgp.org.uk/policy/ rcgp-policy-areas/ /media/Files/Policy/AZ-policy/RCGP-Enhanced-and-ExtendedGP-Training\%20update-April\%202013.ashx laccessed 5 Sep 2016).

9. Ajaz A, Rhodri D, Brown D, Smuk M. BASH: badmouthing, attitudes and stigmatisation in health care as experienced by medical students. BJPsych Bull 2016; 40(2): 97-102. DOI: 10.1192/ pb.bp.115.053140.

10. Baker M, Wessely S, Openshaw D. Not such friendly banter? GPs and psychiatrists against the systematic denigration of their specialties. Br J Gen Pract 2016. DOI: 10.3399/ bjgp16X687169. 